\title{
The characteristics and kinetics of co-pyrolysis of furfural residue with oil shale semi-coke
}

\author{
Yu Yang ${ }^{(a) *}$, Ye Chen ${ }^{(b)}$, Yuchuan Deng ${ }^{(a)}$, Xuanyu Ji ${ }^{(a)}$
}

(a) College of Mechanical and Power Engineering, Chongqing University of Science \& Technology, Chongqing 401331, China

(b) Sichuan Provincial Key Lab of Process Equipment and Control, Zigong 643000, China

Received 3 May 2020, accepted 25 January 2021, available online 10 March 2021

\begin{abstract}
In the present work, the thermogravimetric analysis-Fourier transform infared spectroscopy (TGA-FTIR) system was employed to investigate the co-pyrolysis behavior of oil shale (OS) semi-coke (SC) and furfural residue (FR). Results indicated that the addition of furfural residue improved the pyrolysis characteristics of blends, while synergy behaved differently with the variation of the mixing proportion. Semi-coke could act as a catalyst for the furfural residue pyrolysis and facilitated the release of hydroxyl, but slightly inhibited the release of $\mathrm{CO}_{2}$ and $\mathrm{CH}_{4}$. The optimal blending ratio of oil shale semi-coke to furfural residue was 1:1. Besides, kinetic parameters were calculated using model-free methods, declaring that the sample pyrolysis was a multi-process.
\end{abstract}

Keywords: oil shale semi-coke, furfural residue, co-pyrolysis, interaction, thermogravimetric analysis-Fourier transform infared spectroscopy.

\section{Introduction}

In China, abundant oil shale (OS) resources are retorted for shale oil production to alleviate the shortage of petroleum [1]. The approach to achieve it is using Fushun-type retorts, thus around 10-30 tons of oil shale semi-coke (SC) per ton of shale oil is left after production [2]. Due to the absence of available techniques, landfill is adopted, which, on the one hand, occupies a lot of land, and, on the other hand, causes a great hazard to the environment [3].

Additionally, China is the world's largest producer and exporter of furfural, one of the most important chemicals. Furfural residue (FR) is the solid waste remaining after extracting furfural from corncob. There is generated about 12-15 tons of FR per ton of furfural production, and millions of tons of it

* Corresponding author: e-mail tracycqu@163.com

(C) 2021 Authors. This is an Open Access article distributed under the terms and conditions of the Creative Commons Attribution-NonCommercial 4.0 International License (http://creativecommons.org/licenses/by-nc/4.0/). 
are discharged annually [4]. At the same time, there is no effective method for FR treatment either and the generated FR is dumped in the field directly, resulting in a serious environmental pollution. Hence, there is an urgent need for a clean and effective method to dispose of SC and FR. The co-utilization technology is deemed to be one alternative to handle solid wastes in an environmentally friendly and highly efficient manner. Semi-coke is high-ash and low-carbon, in contrast, low ash and high carbon feature furfural residue. Thus, it is recommended to deal with SC and FR simultaneously to balance each other's disadvantages. Qin et al. [5] proposed that SC should be burnt with FR in the fluidized bed, and investigated co-combustion characteristics using a thermogravimetric analyzer (TGA). The results indicated that with increasing FR mass fraction, the advance ignition and burnout were achieved and combustion characteristics were improved. Synergy occurred in every stage, and the above processes reciprocally promoted each other vigorously only at the SC/FR mass ratio of $4: 6$.

Generally, compared with incineration, pyrolysis is recognized as a more potential and attractive technology for converting raw heterogeneous feedstock into various valuable products. Furfural residue is comprised primarily of cellulose, hemicellulose and lignin and can be separated into high-calorificvalue by-products using pyrolysis techniques [6]. Literature shows that the metal salts of SC exert a promoting or inhibiting effect on the cracking of hydrocarbons depending on the type of biomass. Hu et al. [7] claimed that the inhibiting effect of SC on the co-pyrolysis of OS with C. vulgaris was stronger than their inhibiting effect, while Jiang et al. [8] demonstrated that the addition of SC facilitated the thermal release during the co-pyrolysis of OS with spent mushroom substrate and increased the bio-oil yield.

Up to the present time, studies on the co-pyrolysis of FR and SC have been relatively few, and the mechanism of influence of the latter on FR pyrolysis is still unknown. Furthermore, the development of said process and proper equipment require the understanding of the dominating reaction mechanism, the adoption of optimum pyrolysis parameters as well as the determination of optimum blending ratio [9]. All these factors are important for the subsequent industrial application of the process.

In the present work, the pyrolysis characteristics of $\mathrm{SC}, \mathrm{FR}$ and their blends with different mass ratios at 20,30, 40 and $50{ }^{\circ} \mathrm{C} / \mathrm{min}$ were studied through thermogravimetric analysis (TGA) coupled with Fourier transform infrared spectrometry (FTIR), revealing the pyrolysis behavior of and mutual interaction between the components, as well as the composition of volatile gas products. The activation energy was obtained using the distributed activation energy model (DAEM), Flynn-Wall-Ozawa (FWO) and Kissinger-AkahiraSunose (KAS) methods. Moreover, the optimum blending ratio of FR to SC was figured out for overall consideration. This paper contributes to filling in the gap in the knowledge of the co-pyrolysis of FR and SC and offers reference to its application in industry. 


\section{Experimental methods}

\subsection{Materials}

Semi-coke and furfural were separately collected from the Fushun oil shale retorting plant and the Fushun furfural factory located in Liaoning Province, China. Because of its high moisture content, the drying of FR was needed [5]. Table 1 presents the results of ultimate and proximate analyses of samples. The samples were, in accordance with national standards, ground and sieved from 0 to $0.21 \mathrm{~mm}$. Using a rotary mixer with a stirring shaft, FR was blended with SC in a certain proportion as evenly as possible. The samples at the blending ratios of SC/FR of 1:0, 3:1, 1:1, 1:3 and $0: 1$ were labeled as $\mathrm{S}_{1}, \mathrm{~S}_{2}$, $\mathrm{S}_{3}, \mathrm{~S}_{4}$ and $\mathrm{S}_{5}$.

Table 1. Ultimate and proximate analyses of SC and FR

\begin{tabular}{|c|c|c|c|c|c|c|c|c|c|c|}
\hline \multirow[t]{2}{*}{ Sample } & \multicolumn{5}{|c|}{ Ultimate analysis, wt $\%$} & \multicolumn{4}{|c|}{ Proximate analysis, wt $\%$} & \multirow{2}{*}{$\begin{array}{l}Q_{\text {ad,net' }}, \\
\mathrm{kJ} / \mathrm{kg}\end{array}$} \\
\hline & $\mathrm{C}_{\text {ad }}$ & $\mathrm{H}_{\mathrm{ad}}$ & $\mathrm{O}_{\mathrm{ad}}$ & $\mathrm{N}_{\mathrm{ad}}$ & $\mathrm{S}_{\mathrm{ad}}$ & $\mathrm{M}_{\mathrm{ad}}$ & $\mathrm{V}_{\text {ad }}$ & $\mathrm{A}_{\mathrm{ad}}$ & $\mathrm{FC}_{\mathrm{ad}}$ & \\
\hline $\mathrm{SC}$ & 6.32 & 0.78 & 3.74 & 0.6 & 0.45 & 0.6 & 7.71 & 87.51 & 4.18 & 2403 \\
\hline FR & 48.62 & 5.16 & 36.8 & 0.37 & 0.78 & 3.52 & 68.5 & 4.75 & 23.23 & 17365 \\
\hline
\end{tabular}

\subsection{Apparatus and procedure}

Pyrolysis experiments were performed using a NETZSCH STA 409PC thermogravimetric analyzer (Germany). About $10 \mathrm{mg}$ samples were spread evenly in an alumina crucible under an inert atmosphere of high-purity nitrogen at a flow rate of $40 \mathrm{ml} / \mathrm{min}$ and heated at a rate of 20, 30, 40 and $50{ }^{\circ} \mathrm{C} / \mathrm{min}$, respectively, from room temperature to $1100{ }^{\circ} \mathrm{C}$. For the baseline correction, a separate blank run was conducted using an empty pan at each heating rate. The same experiments were repeated at least twice to ensure the reproducibility of experiments and the accuracy of data.

The gaseous products of the pyrolysis of SC, FR and their blends were determined by a Bruker TENSOR 27 FT-IR spectrometer (Germany). Before experiments, nitrogen was passed through the device for $5 \mathrm{~min}$ to correct the background baseline. The gaseous products travelled through the transfer line which was heated at $180{ }^{\circ} \mathrm{C}$ to prevent the condensation of gases, then the system started to collect the FTIR spectra of gases. The spectra were taken at a wavenumber from $4000 \mathrm{~cm}^{-1}$ to $400 \mathrm{~cm}^{-1}$ with a resolution of $4 \mathrm{~cm}^{-1}$, and 16 scans per sampling. 


\section{Results and discussion}

\subsection{Pyrolysis characteristics of samples}

TG and DTG curves of samples at a heating rate of $40{ }^{\circ} \mathrm{C} / \mathrm{min}$ are displayed in Figures $1 \mathrm{a}$ and $1 \mathrm{~b}$, respectively. The pyrolysis process of samples could be roughly divided into three stages. In the first stage, a slight mass loss occurred below $150{ }^{\circ} \mathrm{C}$, which was attributed to the loss of free water and interlayer water. As the temperature rose, there was observed an obvious weight loss, corresponding to the devolatilization of FR. The thermal degradation of FR occurred in the temperature range from 200 to $600{ }^{\circ} \mathrm{C}$ and consisted of two stages. In the first stage, a sharp mass loss peak appearing at $200-400{ }^{\circ} \mathrm{C}$ was ascribed to the decomposition of cellulose, hemicellulose and partial lignin. In the second stage, a mass loss shoulder formed at $400-600{ }^{\circ} \mathrm{C}$ was related to the continuous devolatilization of FR with some lignin and char [10]. Besides, the thermal decomposition of SC took place at $450-650{ }^{\circ} \mathrm{C}$, and there was only an unapparent region in its DTG curve. The reason was that in the retorting process of OS, most of organic matter was decomposed, thus the weight loss of SC at this stage was attributed to the degradation of low-molecularweight residual organic matter. When the temperature was further raised to approximately $700{ }^{\circ} \mathrm{C}$, some minerals underwent thermal decomposition and their TG and DTG curves gradually became smooth [11]. Thus, in general, the pyrolysis process of FR, SC and their blends could be divided into the phases of water evaporation, and decomposition of organic and inorganic matter.

Figure 1 also reveals that all the TG and DTG curves of blends were formed between those of onefold components. The tendency refers to that with increasing FR mass fraction, the total weight loss, pyrolysis range width and maximum weight loss rate increased, showing that FR contained more volatile matter and its pyrolysis behavior was superior to that of SC. This was consistent with proximate analysis results. Hence, it was claimed that the addition of FR improved the pyrolysis performance of blended samples.

(a)

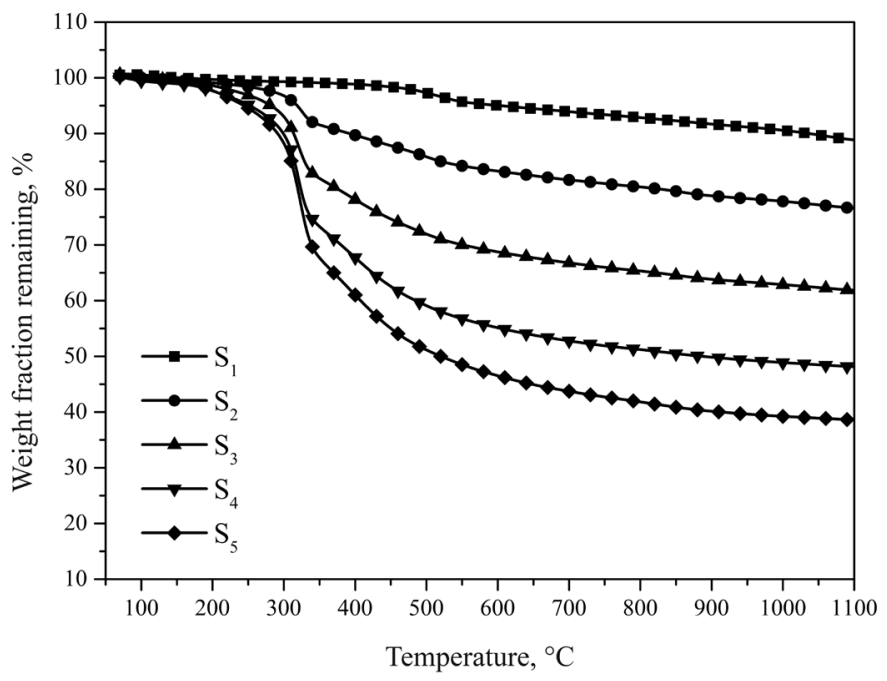


(b)

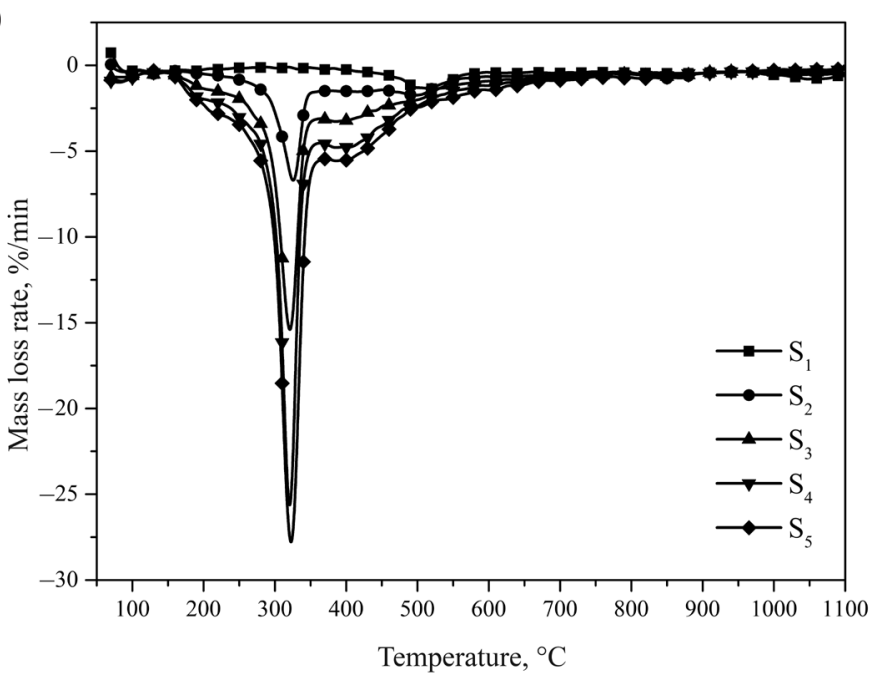

Fig. 1. TG (a) and DTG (b) curves of samples $\mathrm{S}_{1}-\mathrm{S}_{5}$ at a heating rate of $40{ }^{\circ} \mathrm{C} / \mathrm{min}$.

Figure 2 shows the TG and DTG curves of sample $\mathrm{S}_{2}$ at different heating rates. It can be seen from the figure that with increasing heating rate, the maximum weight loss rate and peak temperature increased and the DTG curve moved toward higher temperature. This could be explained by the shortening of the reaction time with increasing heating rate, which was unfavourable for the pyrolysis process. Also, the temperature and pressure gradient of the exterior and interior of the sample rose, resulting in the increase of heat diffusion resistance, after which the thermal hysteresis occurred. However, the sample underwent a stronger thermal shock at a higher heating rate, which enhanced the intensity of pyrolysis.

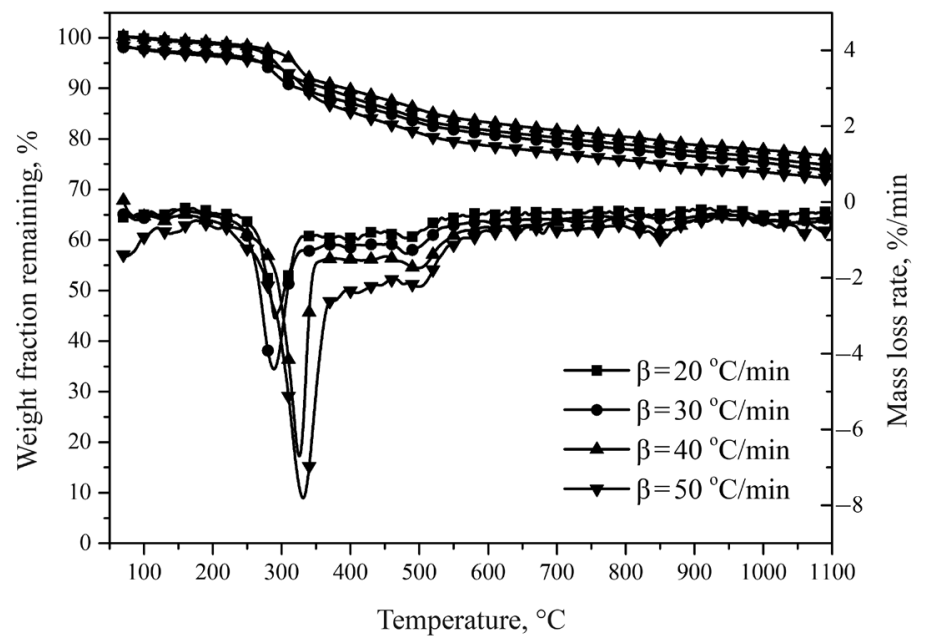

Fig. 2. TG and DTG curves of sample $\mathrm{S}_{2}$ at different heating rates. 
In this work, a pyrolysis index $(D)$ was used to evaluate the pyrolysis characteristics of FR, SC and their blends, as described by Equation (1) [12]:

$$
D=\frac{(d w / d t)_{\max }(d w / d t)_{\text {mean }} M_{\infty}}{T_{i} T_{\max } \Delta T_{1 / 2}}
$$

where $(d w / d t)_{\max }$ and $(d w / d t)_{\text {mean }}$ represent the maximum and average mass loss rate, respectively, $M_{\infty}$ is the mass loss, $T_{\mathrm{i}}$ is the initial temperature determined by extrapolating TG-DTG data, $T_{\max }$ and $\Delta T_{1 / 2}$ are the temperature of maximum mass loss rate and peak half-width, respectively. A higher value of $D$ suggested the better pyrolysis release characteristics of the sample.

Table 2 presents the pyrolysis characteristics of samples at a heating rate of $40{ }^{\circ} \mathrm{C} / \mathrm{min}$. It is obvious that when the FR mass fraction was increased from 0 to $25 \%, T_{\mathrm{i}}$ and $T_{\max }$ decreased respectively from 460 to $299{ }^{\circ} \mathrm{C}$ and from 524.5 to $325.6{ }^{\circ} \mathrm{C}$, indicating that the pyrolysis process was accelerated by adding FR. Also, with increasing FR mass fraction, $D$ increased from $0.03 \times 10^{-11} \mathrm{~min}^{-2}{ }^{\circ} \mathrm{C}^{-3}$ to $128.96 \times 10^{-11} \mathrm{~min}^{-2}{ }^{\circ} \mathrm{C}^{-3}$, demonstrating that the addition of FR improved the pyrolysis characteristics of samples. On the other hand, the experimental values of pyrolysis characteristics of blends did not agree with calculated ones, giving evidence of interactions between SC and FR.

Table 2. The pyrolysis characteristics of samples at a heating rate of $40{ }^{\circ} \mathrm{C} / \mathrm{min}$

\begin{tabular}{|c|c|c|c|c|c|c|c|}
\hline Sample & $\begin{array}{c}T_{\mathrm{i},} \\
{ }^{\circ} \mathrm{C}\end{array}$ & $\begin{array}{c}T_{\max }, \\
{ }^{\circ} \mathrm{C}\end{array}$ & $\begin{array}{c}\Delta T_{1 / 2}, \\
{ }^{\circ} \mathrm{C}\end{array}$ & $\begin{array}{c}(d w / d t)_{\max }, \\
\% / \mathrm{min}\end{array}$ & $\begin{array}{c}(d w / d t)_{\text {mean }} \\
\% / \mathrm{min}\end{array}$ & $\begin{array}{c}M_{\infty}, \\
\%\end{array}$ & $\begin{array}{c}\mathrm{D} \times 10^{11}, \\
\mathrm{~min}^{-2}{ }^{\circ} \mathrm{C}^{-3}\end{array}$ \\
\hline $\mathrm{S}_{1}$ & 460 & 524.5 & 88.2 & -1.38 & -0.42 & 11.13 & 0.03 \\
$\mathrm{~S}_{2}$ & 299 & 325.6 & 33.9 & -6.7 & -0.88 & 23.41 & 4.18 \\
$\mathrm{~S}_{2, \mathrm{cal}}$ & 417.8 & 474 & 74.3 & -7.98 & -0.89 & 23.7 & 1.14 \\
$\mathrm{~S}_{3}$ & 295 & 321.1 & 32.4 & -15.4 & -1.43 & 38.12 & 27.35 \\
$\mathrm{~S}_{3, \text { cal }}$ & 375.5 & 423.6 & 60.3 & -14.58 & -1.36 & 36.26 & 7.5 \\
$\mathrm{~S}_{4}$ & 292.1 & 320.8 & 26.1 & -25.62 & -1.94 & 51.83 & 105.39 \\
$\mathrm{~S}_{4, \text { cal }}$ & 333.3 & 373 & 46.4 & -21.18 & -1.83 & 48.83 & 32.81 \\
$\mathrm{~S}_{5}$ & 291 & 322.6 & 32.4 & -27.78 & -2.3 & 61.39 & 128.96 \\
\hline
\end{tabular}




\subsection{Synergy between blended samples}

To verify the coupling interactions and explore the underlying mechanism during the co-pyrolysis of SC and FR, the theoretical TG and DTG curves were calculated and the synergy was quantitatively determined by the interaction coefficient $(f)$ and the relative error of mean square root $(r m s)$ [13], as described by Equations (2)-(5):

$$
\begin{gathered}
M_{\mathrm{cal}}=x_{\mathrm{SC}} M_{\mathrm{SC}}+x_{\mathrm{FR}} M_{\mathrm{FR}}, \\
\left(\frac{d w}{d t}\right)_{\mathrm{cal}}=x_{\mathrm{SC}}\left(\frac{d w}{d t}\right)_{\mathrm{SC}}+x_{\mathrm{FR}}\left(\frac{d w}{d t}\right)_{\mathrm{FR}} \\
f=\frac{R_{\mathrm{exp}} \Delta T_{1 / 2, \mathrm{exp}} / T_{\text {max, exp }}}{R_{\mathrm{cal}} \Delta T_{1 / 2, \mathrm{cal}} / T_{\mathrm{max}, \mathrm{cal}}}, \\
r m s=\sqrt{\frac{\sum_{i}^{n}\left(\frac{x_{\mathrm{exp}}^{i}-x_{\mathrm{cal}}^{i}}{x_{\mathrm{cal}}^{i}}\right)^{2}}{n}},
\end{gathered}
$$

where $x$ is the mass fraction of each individual fuel in the mixture, $M$ and $(d w / d t)$ are respectively the residue mass loss and the mass loss rate of an individual fuel, $R$ is the value of DTG peak point, $\Delta T_{1 / 2}$ is the peak half-width, $x^{\mathrm{i}}$ is the weight fraction remaining of NO. i, and $n$ is the number of points selected in the experiment.

Figure 3 illustrates the experimental and calculated curves of blends at a heating rate of $40{ }^{\circ} \mathrm{C} / \mathrm{min}$. It is clear that the co-pyrolysis of FR and SC is not a simple superposition of these components, but also involves their mutual influences. Table 3 lists the synergy evaluation parameters of the mixture of SC and FR. As mentioned above, synergy behaved differently with the variation of proportions of the blend components. When the SC mass fraction was 25 or $50 \%$, the experimental values of total weight loss and maximum mass loss rate were both higher than calculated ones, and the value of $f$ was larger than 1 , suggesting positive interactions between SC and FR. However, the case was opposite with the sample of $75 \%$ SC mass fraction, the experimental values of total weight loss and maximum mass loss rate of which were slightly smaller than calculated ones, and the $f$ value was smaller than 1 . This implied negative interactions between SC and FR and an undesirable course of the co-pyrolysis process. This might be explained by the presence of minerals such as $\mathrm{SiO}_{2}$, $\mathrm{Al}_{2} \mathrm{O}_{3}, \mathrm{Fe}_{2} \mathrm{O}_{3}$ and $\mathrm{CaO}$ in $\mathrm{SC}$ [14]. Previously it has been demonstrated that the active acid sites in $\mathrm{Al}_{2} \mathrm{O}_{3}$ could catalyze the decomposition of biomass [8]. 
Also, alkali and alkaline earth metal elements were able to exert a catalytic effect on the pyrolysis of biomass [15]. Moreover, the presence of SC could enhance the heat transfer among solid particles [16]. Thus, all the above factors combined together accelerated the decomposition of FR. On the other hand, the larger amount of SC particles in the blend might coat the FR powder, thus increasing the absorption effect, as well as the resistance to heat and mass transfer [17]. This hampered the release of volatile matter from FR. Hence, it could be further concluded that the pyrolysis process of FR was delayed by too high a proportion of SC. Considering the above, in order to promote the decomposition of FR and hinder that of SC, the optimal blending ratio of FR and SC was selected to be $1: 1$.
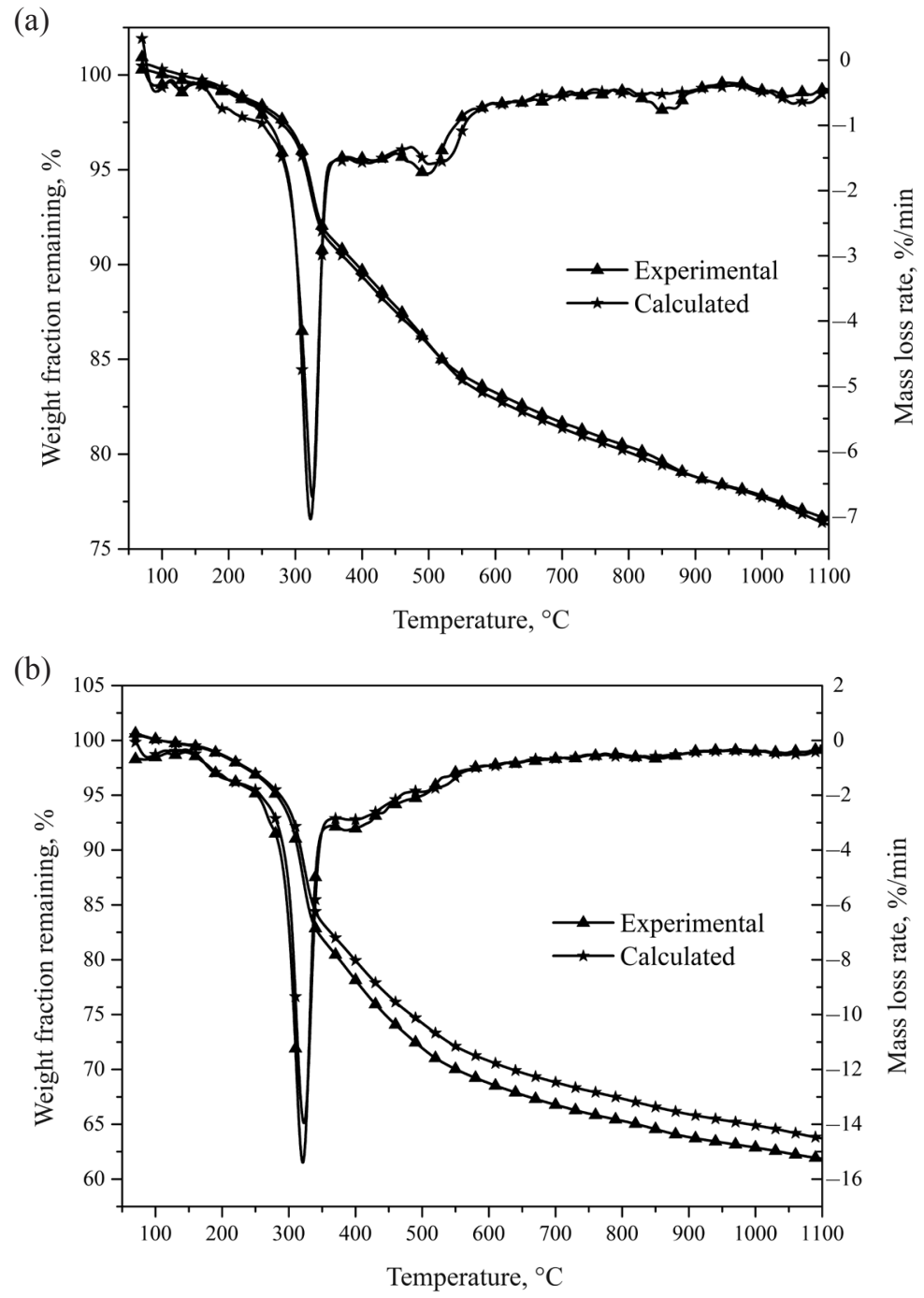


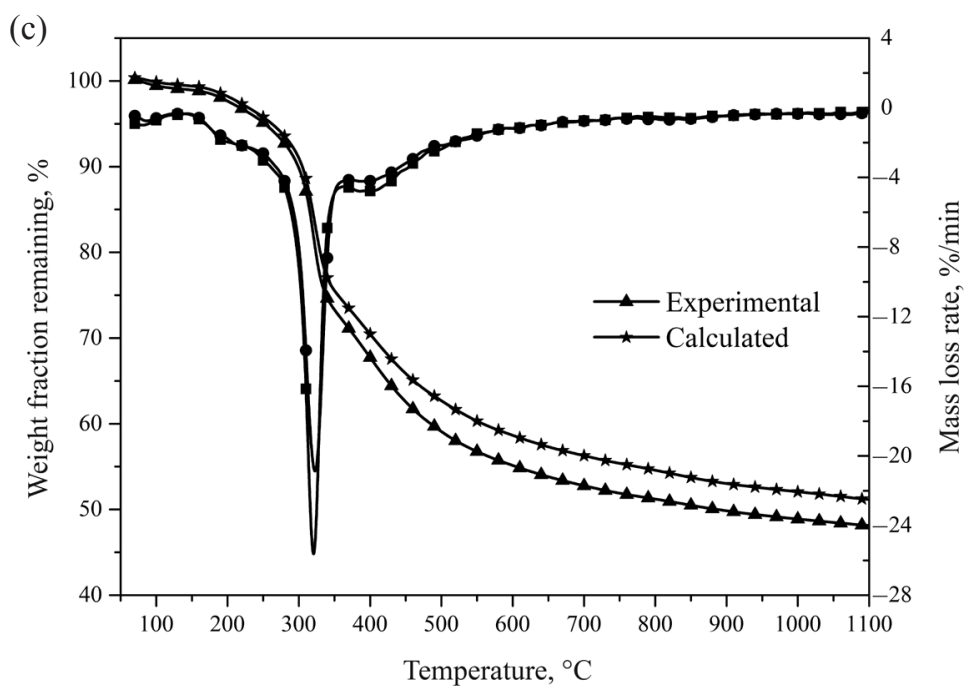

Fig. 3. Comparison between the experimental and calculated curves of samples $\mathrm{S}_{2}$ (a), $\mathrm{S}_{3}$ (b) and $\mathrm{S}_{4}$ (c) at a heating rate of $40^{\circ} \mathrm{C} / \mathrm{min}$.

Table 3. Synergy evaluation parameters of blended samples

\begin{tabular}{|c|c|c|}
\hline Sample & $f$ & $r m s$ \\
\hline $\mathrm{S}_{2}$ & 0.97 & 0.003 \\
$\mathrm{~S}_{3}$ & 1.11 & 0.021 \\
$\mathrm{~S}_{4}$ & 1.21 & 0.042 \\
\hline
\end{tabular}

\subsection{TGA-FTIR of gaseous products}

Figure 4 shows the three-dimensional infrared adsorption spectra of sample $\mathrm{S}_{3}$ at a heating rate of $20^{\circ} \mathrm{C} / \mathrm{min} . \mathrm{S}_{3}$ can be seen to contain several gaseous products, such as carbonyl, hydroxyl, carbon dioxide, carbon monoxide, methane, etc. The peaks at $1734 \mathrm{~cm}^{-1}$ and $1220 \mathrm{~cm}^{-1}$ were attributed to carbonyl and hydroxyl groups, confirming the presence of aldehydes or organic acid, and alcohols or phenols [6]. The breaking of both the methoxy group with lower bond energy and the methylene group with higher bond energy led to the release of $\mathrm{CH}_{4}$. The bands at $2384 \mathrm{~cm}^{-1}$ and $2184 \mathrm{~cm}^{-1}$ indicated the formation of $\mathrm{CO}_{2}$ and $\mathrm{CO}$, respectively, which was generally caused by the cracking of carbonyl [18]. Moreover, the band at $3733 \mathrm{~cm}^{-1}$ was assigned to the stretching of the $\mathrm{O}-\mathrm{H}$ bond, corresponding to the release of $\mathrm{H}_{2} \mathrm{O}$, which was probably produced by the cleavage of aliphatic hydroxyl groups in the side chains of organic polymers [19]. 


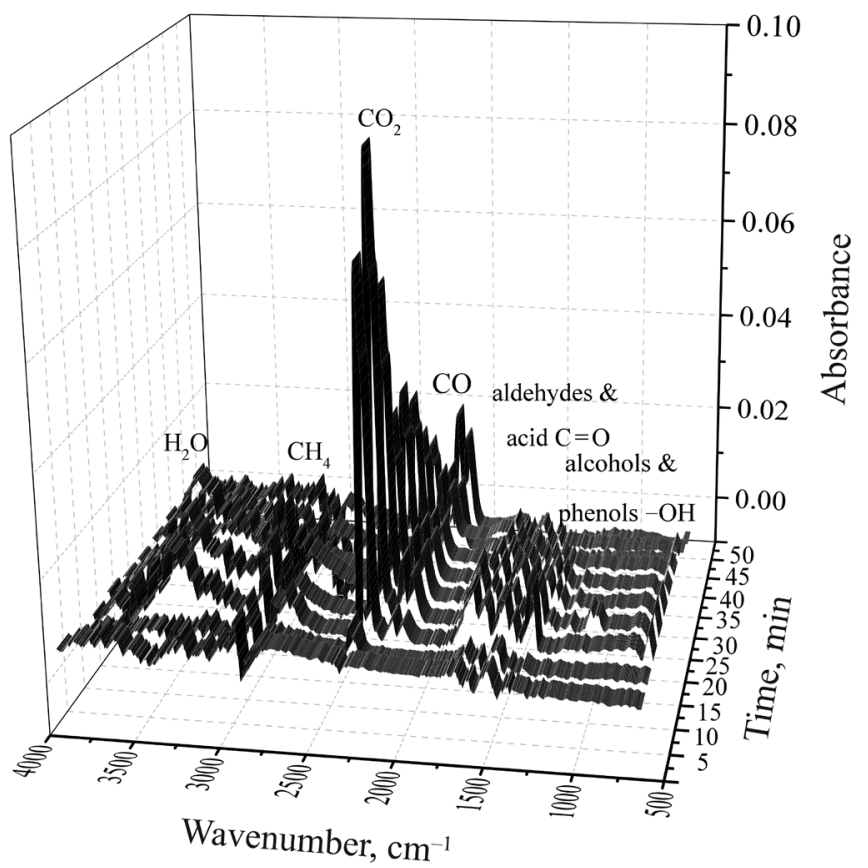

Fig. 4. Three-dimensional infrared absorption spectra in the pyrolysis process of sample $\mathrm{S}_{3}$.

The Lambert-Beer law suggests that the absorption spectrum at a specific wavenumber linearly depends on gas concentration, and the variation in FTIR peak height reflects the change tendency of gaseous products concentration. Thus, absorbance data at different temperatures can be obtained by fixing the wavenumber to determine the release characteristics of samples, as illustrated in Figure 5. From the figure it can be seen that except $\mathrm{CO}$ and $\mathrm{CO}_{2}$, other gaseous products had one intense absorption peak, while the emission intensity increased before the appearance of the peak in the temperature range of $350-450{ }^{\circ} \mathrm{C}$, decreasing thereafter with rising temperature. The addition of SC facilitated the release of hydroxyl, but slightly inhibited that of $\mathrm{CO}_{2}$ and $\mathrm{CH}_{4}$. Besides, it is worthy of note that the rate of release and the total volume of the released compounds were different, yet there was a positive relationship between the release rate of gaseous products and the proportion of FR. 
(a)

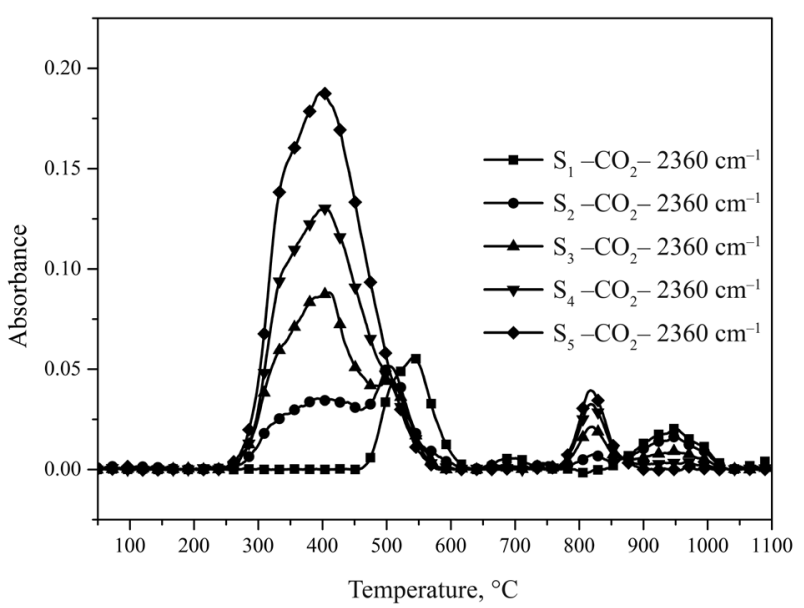

(b)

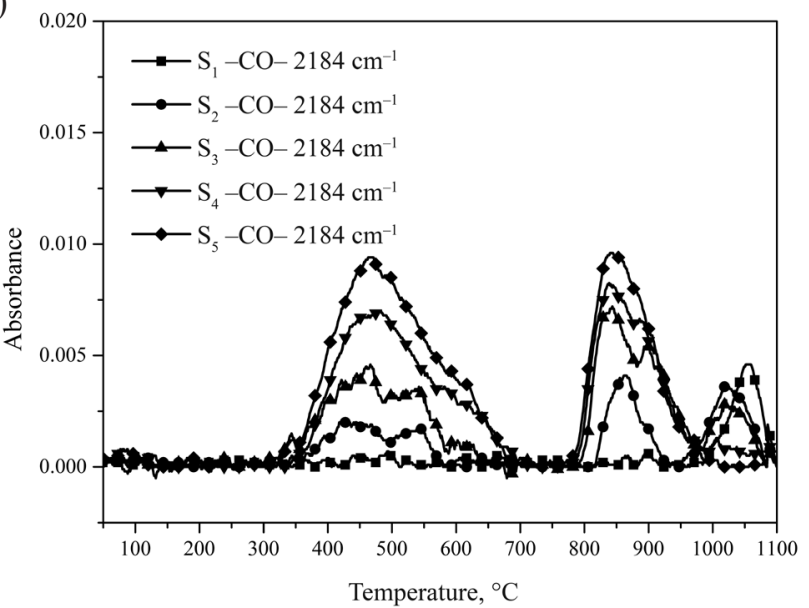

(c)

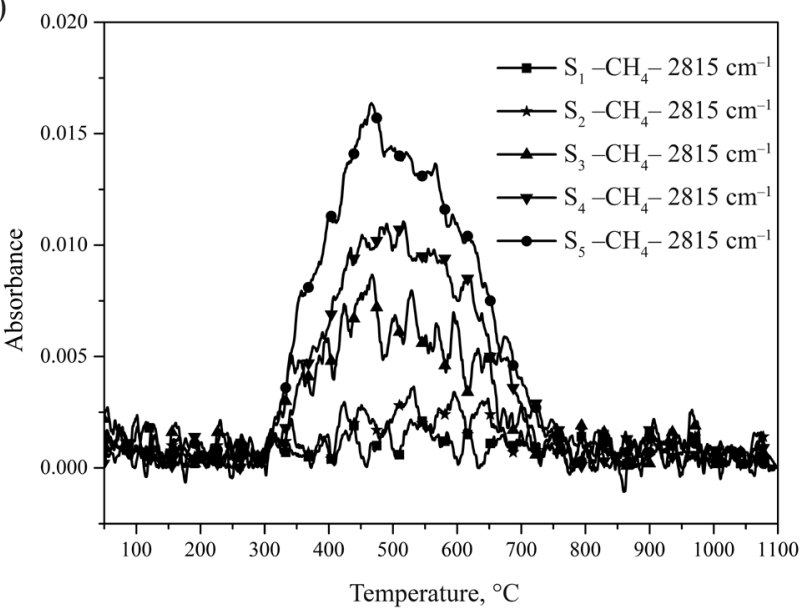


(d)

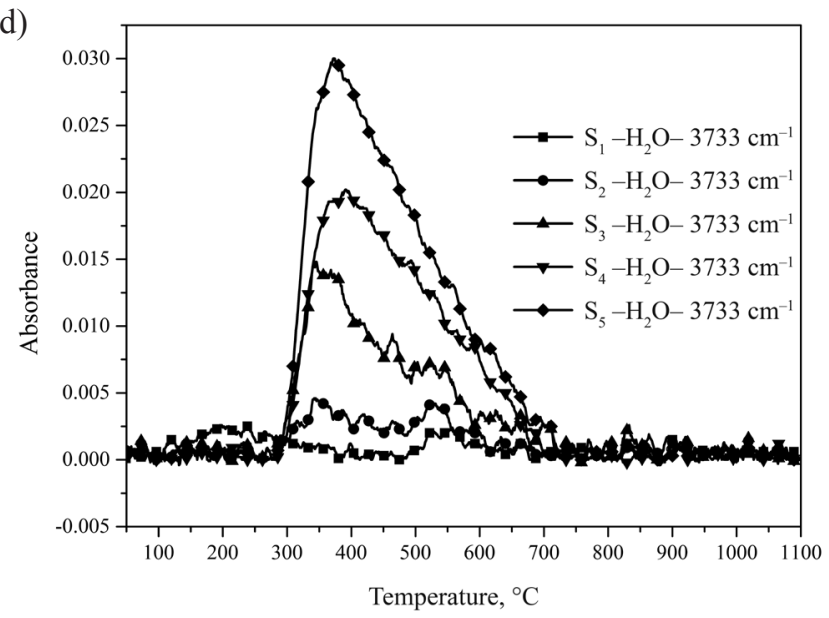

(e)

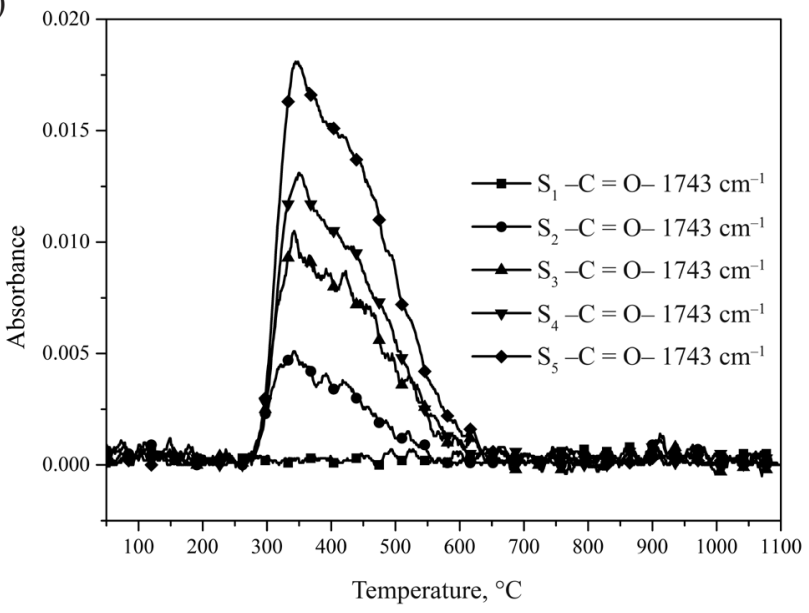

(f)

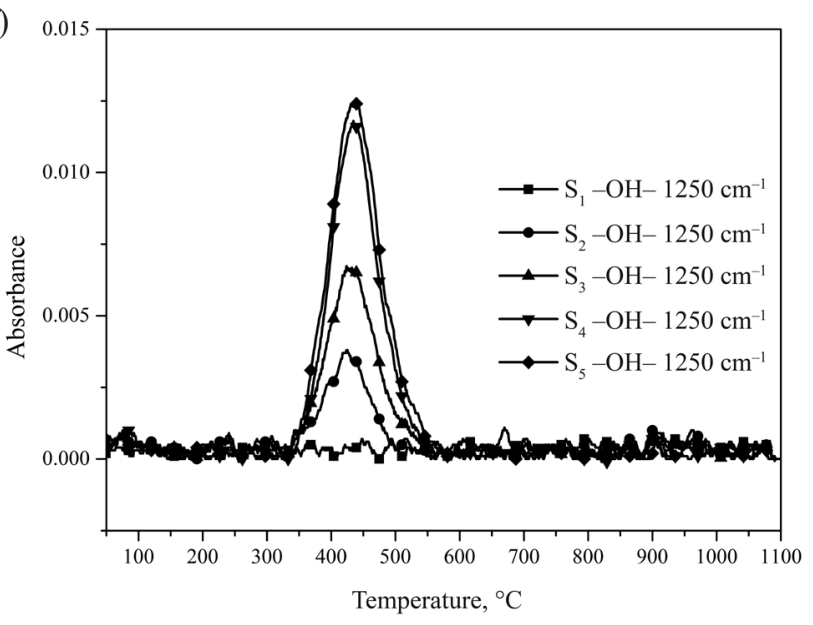

Fig. 5. Gaseous products release rules of samples $\mathrm{S}_{1}-\mathrm{S}_{5}$. 


\subsection{Kinetic analysis}

In this work, three kinds of model-free methods (DAEM, FWO, KAS) were used to calculate the activation energy, the corresponding equations being as follows [20]:

$$
\begin{gathered}
\frac{E}{R}=-\frac{d \ln \beta}{d(1 / T)}-2 T, \\
\lg \beta=\lg \left(\frac{A E}{G(\alpha)}\right)-2.315-0.4567 \frac{E}{R T}, \\
\ln \frac{\beta}{T^{2}}=\ln \left(\frac{A R}{G(\alpha) E}\right)-\frac{E}{R T},
\end{gathered}
$$

where $\alpha$ is the conversion degree; $\beta$ is the heating rate; $A, E, R$ and $T$ are respectively the frequency factor, activation energy, universal gas constant and temperature. Hence, if to plot $\ln \beta, \lg \beta$ or $\ln (\beta / T)^{2}$ vs $1 / T$ at selected $\alpha$, the slope of the curve at different $\alpha$ values is obtained. Then, $E$ values corresponding to $\alpha$ values can be obtained.

The activation energy curves of samples $\mathrm{S}_{2}-\mathrm{S}_{5}$ at $\alpha=0.1-0.9$ in the devolatilization temperature range of $200-600{ }^{\circ} \mathrm{C}$ are shown in Figure 6. The correlation coefficients of $E$ were greater than 0.91 , implying an acceptable accuracy of the results. The laws governing the change of $E$ established through DAEM, FWO and KAS were similar, and differences in $E$ values among the above methods were smaller than $7 \mathrm{~kJ} / \mathrm{mol}$, suggesting that either of them could be used to calculate the pyrolysis kinetics of samples. As seen from Figures $6 \mathrm{a}-6 \mathrm{c}, E$ gradually increased with progressing conversion, indicating the complex nature of the pyrolysis process of a sample. In addition, with increasing SC mass fraction, $E$ increased uniformly, remaining mainly in the range of $50-140 \mathrm{~kJ} / \mathrm{kg}$.

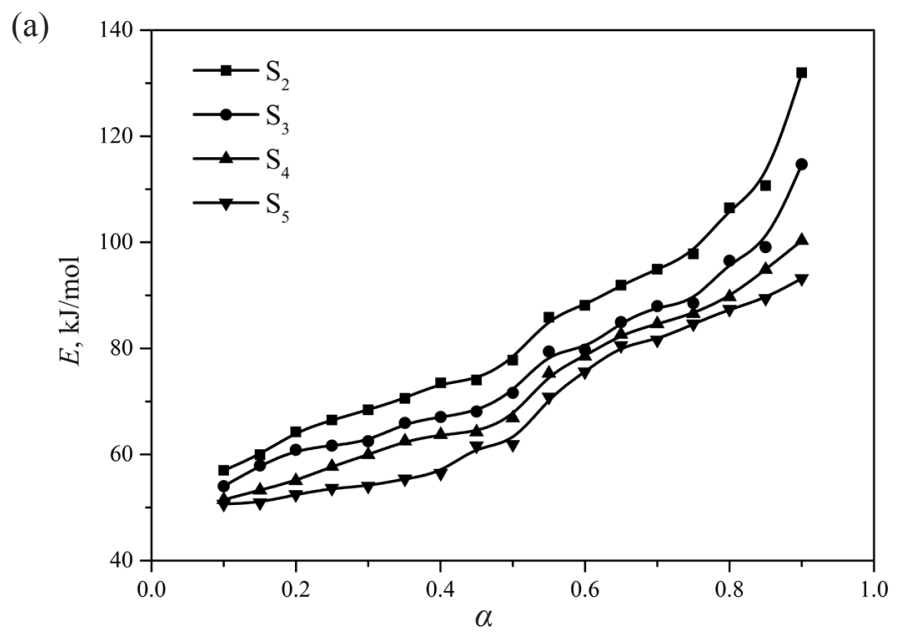


(b)

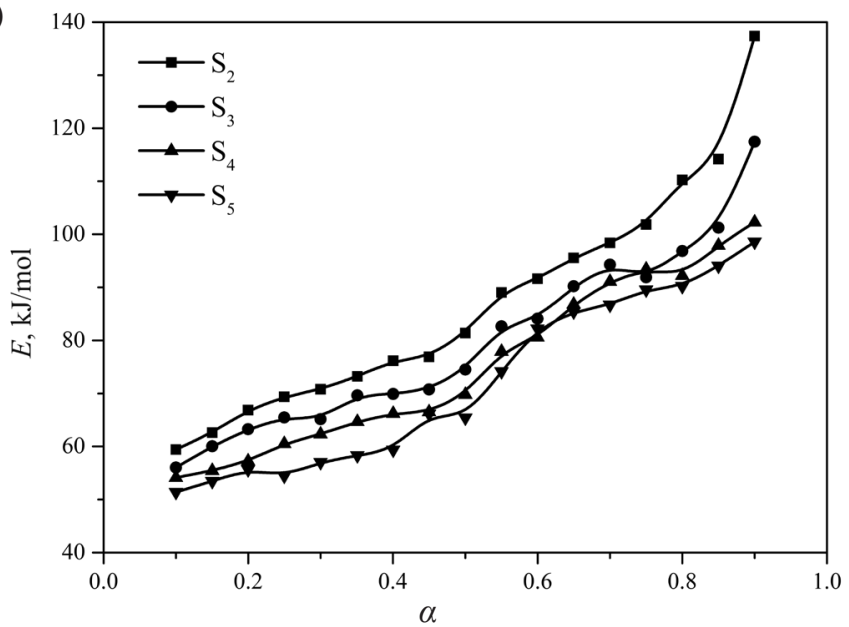

(c)

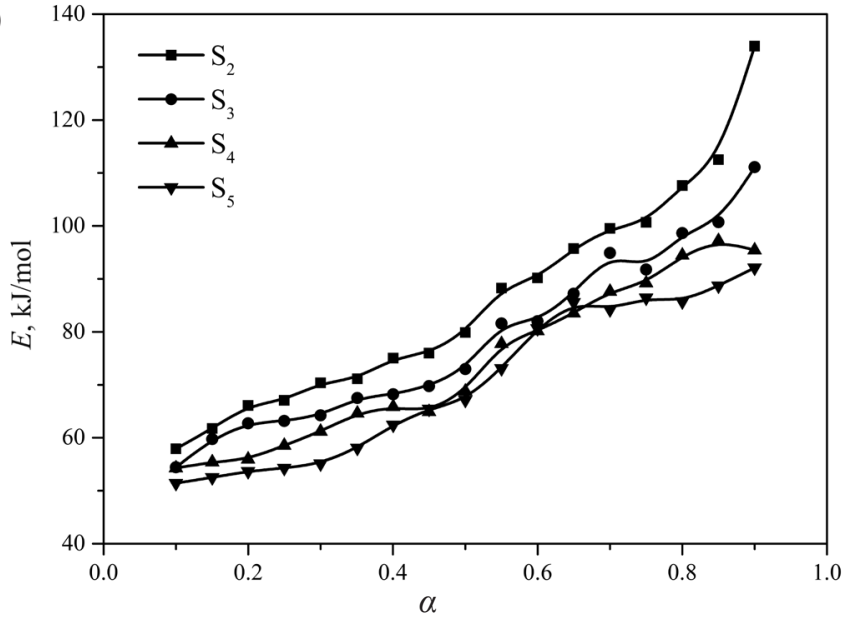

Fig. 6. The relationship between $E$ and $\alpha$ of samples $\mathrm{S}_{2}-\mathrm{S}_{5}$ by DAEM (a), FWO (b) and KAS (c) methods.

\section{Conclusions}

The co-pyrolysis characteristics of oil shale semi-coke and furfural residue were studied by thermogravimetric analysis coupled with Fourier transform infrared spectrometry. Some primary results are summarized as follows:

1. The pyrolysis performance of blends improved with increasing furfural residue proportion. The co-pyrolysis of blends was not a simple superposition of individual components, but also involved their mutual influences. 
2. Synergy behaved differently with the variation of the mixing ratio. The interaction between the blend components was favourable for co-pyrolysis when the semi-coke mass fraction was $25 \%$ or $50 \%$, and unfavorable at said fraction of $75 \%$. Hence, it was recommended to use the semi-coke fraction of $50 \%$.

3. The addition of semi-coke facilitated the release of hydroxyl, but slightly inhibited the release of $\mathrm{CO}_{2}$ and $\mathrm{CH}_{4}$.

4. The co-pyrolysis of semi-coke and furfural residue was a multi-process, and its kinetic parameters could be calculated using the distributed activation energy model, Flynn-Wall-Ozawa and Kissinger-Akahira-Sunose methods.

In summary, the industrial application of co-pyrolysis of oil shale semi-coke and furfural residue may have a good prospect, while at a certain mixing ratio semi-coke can act as a catalyst for the pyrolysis of furfural residue.

\section{Acknowledgments}

This work was funded by the Science and Technology Research Program of Chongqing Municipal Education Commission (No. KJQN201901521), Sichuan Provincial Key Lab of Process Equipment and Control (No. GK202003) and Chongqing Municipal Solid Waste Resource Utilization \& Treatment Collaborative Innovation Center (No. shljzyh2018-004).

\section{REFERENCES}

1. Jiang, X. M., Han, X. X., Cui, Z. G. New technology for the comprehensive utilization of Chinese oil shale resources. Energy, 2007, 32(5), 772-777.

2. Jiang, X. M., Han, X. X., Cui, Z. G. Progress and recent utilization trends in combustion of Chinese oil shale. Prog. Energy Combust. Sci., 2007, 33(6), 552-579.

3. Pae, T., Luud, A., Sepp, M. Artificial mountains in North-East Estonia: Monumental dumps of ash and semi-coke. Oil Shale, 2005, 22(3), 333-343.

4. Wang, Y., Xu, Z. Y., Song, X., Yang, B., Zhang, D. The preparation of low-cost adsorbent for heavy metal based on furfural residue. Mater. Manuf. Process., 2017, 32(1), 87-92.

5. Qin, H., Wang, W., Liu, H. P., Zhang, L. D., Wang, Q., Shi, C. Y., Yao, K. W. Thermal behavior research for co-combustion of furfural residue and oil shale semi-coke. Appl. Therm. Eng., 2017, 120, 19-25.

6. Quan, C., Ma, Z. Z., Gao, N. B., He, C. Pyrolysis and combustion characteristics of corncob hydrolysis residue. J. Anal. Appl. Pyrolysis, 2018, 130, 72-78.

7. Hu, Z. F., Ma, X. Q., Li, L. J. The synergistic effect of co-pyrolysis of oil shale 
and microalgae to produce syngas. J. Energy Inst., 2016, 89(3), 447-455.

8. Jiang, H. F., Zhang, M. Y., Chen, J., Li, S., Shao, Y. F., Yang, J. Q., Li, J. F. Characteristics of bio-oil produced by the pyrolysis of mixed oil shale semi-coke and spent mushroom substrate. Fuel, 2017, 200, 218-224.

9. He, Y., Ma, X. Q. Comparative investigation on non-isothermal kinetics for thermo-degradation of lignocellulosic substrate and its chlorinated derivative in atmospheres with $\mathrm{CO}_{2}$ participation. Bioresour. Technol., 2015, 189, 71-80.

10. Zhang, X. S., Lei, H. W., Zhu, L., Qian, M., Yadavalli, G., Wu, J., Chen, S. L. Thermal behavior and kinetic study for catalytic co-pyrolysis of biomass with plastics. Bioresour. Technol., 2016, 220, 233-238.

11. Williams, P. T., Ahmad, N. Investigation of oil-shale pyrolysis processing conditions using thermogravimetric analysis. Appl. Energy, 2000, 66(2), 113-133.

12. Fang, S. W., Yu, Z. S., Lin, Y. S., Hu, S. C., Liao, Y. F., Ma, X. Q. Thermogravimetric analysis of the co-pyrolysis of paper sludge and municipal solid waste. Energy Convers. Manag., 2015, 101, 626-631.

13. Qin, H., Yue, Y. K., Zhang, L., Liu, Y. Y., Chi, M. S., Liu, H. P., Wang, Q., Liu, B. Study on co-combustion kinetics of oil shale sludge and semi-coke. Energy Fuels, 2016, 30(3), 2373-2384.

14. Yang, Y., Lu, X. F., Wang, Q. H., Mei, L., Song, D. C., Hong, Y. Experimental study on combustion of low calorific oil shale semicoke in fluidized bed system. Energy Fuels, 2016, 30(11), 9882-9890.

15. Nguyen, T. S., Zabeti, M., Lefferts, L., Brem, G., Seshan, K. Conversion of lignocellulosic biomass to green fuel oil over sodium based catalysts. Bioresour. Technol., 2013, 142, 353-360.

16. Niu, M. T., Wang, S., Han, X. X., Jiang, X. M. Yield and characteristics of shale oil from the retorting of oil shale and fine oil-shale ash mixtures. Appl. Energy, 2013, 111, 234-239.

17. Grierson, S., Strezov, V., Ellem, G., Mcgregor, R., Herbertson, J. Thermal characterisation of microalgae under slow pyrolysis conditions. J. Anal. Appl. Pyrolysis, 2009, 85(1-2), 118-123.

18. Qin, L. B., Han, J., He, X., Zhan, Y. Q., Yu, F. Recovery of energy and iron from oily sludge pyrolysis in a fluidized bed reactor. J. Environ. Manage., 2015, 154, 177-182.

19. Meng, A. H., Zhou, H., Qin, L., Zhang, Y. G., Li, Q. H. Quantitative and kinetic TG-FTIR investigation on three kinds of biomass pyrolysis. J. Anal. Appl. Pyrolysis, 2013, 104, 28-37.

20. Yang, Y., Lu, X. F., Wang, Q. H. Investigation on the co-combustion of low calorific oil shale and its semi-coke by using thermogravimetric analysis. Energy Convers. Manag., 2017, 136, 99-107. 